\title{
ARTIGOS
}

\section{FORMAÇÃO DE PROFESSORES: LIMITES E DESAFIOS NA EDUCAÇ̃̃O SUPERIOR}

\author{
ANTONIO GERMANO MAGALHÃES JÚNIOR' \\ MÔNICA DUARTE CAVAIGNAC"
}

\section{RESUMO}

Este artigo procura realizar uma reflexão acerca dos resultados de uma pesquisa financiada a partir de edital público, com o propósito de cartografar a formação, as práticas e os saberes dos professores dos cursos de licenciatura de uma universidade pública estadual. A investigação, de natureza qualitativa, envolveu estudos bibliográficos, documentais e de campo que se constituíram em dissertações, teses e estágio pós-doutoral na área de formação de professores, os quais apontaram a insuficiência de formação pedagógica dos docentes, inclusive daqueles que formam professores, a precarização das relações e condições de trabalho na instituição de ensino investigada e a falta de recursos públicos para suprir as demandas profissionais e institucionais.

\section{EDUCAÇÃO SUPERIOR • FORMAÇÃO DE PROFESSORES • TRABALHO DOCENTE}

TEACHER EDUCATION: CONSTRAINTS AND CHALLENGES IN HIGHER EDUCATION

\section{ABSTRACT}

This article reflects on the results of a study funded by the public announcement, with the purpose of mapping the education, practices the knowledge of the professors of the teacher education programs of a public state university. This qualitative research involved bibliographical, documentary and field studies which resulted in master theses, doctoral dissertations and a postdoctoral internship in the field of teacher education, which indicated the insufficient pedagogical training of teachers, including of those who train teachers, the deterioration of 


\section{FORMATION DES ENSEIGNANTS: LIMITES ET} DÉFIS DE L'ÉDUCATION SUPÉRIEURE

\section{RÉSUMÉ}

Cet article essaye de réflechir sur les résultats d'une recherche financée par l'appel public dans le but de cartographier la formation, les pratiques et les savoirs des professeurs dans une université publique. La recherche, de nature qualitative, a pris en considération des études de documents et bibliographiques et des recherches sur le terrrain, sous forme de mémoires, thèses et rapports de stages post-doctoraux au sujet de la formation des enseignants. Les résultats ont signalé non seulement une insuffisance en matière de formation pédagogique, y comprise celle des professeurs, mais aussi la précarisation des rélations et des conditions de travail dans cette université, ainsi qu'un manque de ressources publiques pour pourvoir aux demandes professionnelles et institutionnelles.

ÉDUCATION SUPÉRIEURE • FORMATION DES ENSEIGNANTS • TRAVAIL D'ENSEIGNEMENT

RESUMEN

Este artículo pretende efectuar una reflexión acerca de los resultados de una investigación financiada a partir del edicto público, con el propósito de cartografiar la formación, prácticas y saberes de los profesores de los cursos de licenciatura de una universidad pública provincial. La investigación, de naturaleza cualitativa, abarcó estudios bibliográficos, documentales y de campo constituidos por disertaciones, tesis y estadío postdoctoral en el área de formación de profesores, los cuales señalaron la insuficiencia de formación pedagógica de los docentes, incluso de aquellos que forman profesores, la precarización de las relaciones y condiciones laborales en la institución de enseñanza investigada y la falta de recursos públicos para suplir las demandas profesionales e institucionales. 
TEMÁtICA FORMAÇÃo dE PROFESSORES É OBJETO COTIDIANO dE DEBATES NÃO somente no meio universitário, mas também no noticiário na mídia nacional. Os resultados de avaliações dos processos de aprendizagem em diversos níveis e modalidades de ensino colocam sobre a profissão docente uma espécie de lupa de observação, gerando questionamentos e interesses de diferentes setores da sociedade.

O propósito deste artigo é realizar uma reflexão acerca dos resultados da pesquisa intitulada "Cartografia das relações de saber/ poder dos professores das licenciaturas”, inscrita na área de Formação de Professores do Programa de Pós-graduação em Educação (PPGE) da Universidade Estadual do Ceará (Uece). A pesquisa, de natureza prioritariamente qualitativa, foi realizada entre 2014 e 2017, sendo uma atividade financiada a partir do edital público do Conselho Nacional de Desenvolvimento Científico e Tecnológico (CNPq) Chamada Universal 2014. Seu objetivo geral foi cartografar a constituição das relações de saber/poder, a formação, as práticas e os saberes dos professores dos cursos de licenciatura da Uece, especialmente daqueles que assumem disciplinas e atividades destinadas à formação pedagógica.

Como locus privilegiado de mobilização e sistematização do conhecimento profissional docente, a Uece vem contribuindo consideravelmente para a formação dos quadros de professores que atendem a rede de educação básica do Nordeste brasileiro nos últimos 30 anos, sendo hoje constituída por uma rede multicampi, com dois campi na ca- 
pital e seis em cidades do interior do estado, nos quais são ofertados diversos cursos de licenciatura em diferentes áreas do conhecimento: Geografia, Física, Química, Ciências Biológicas, Matemática, Música, Letras (Português, Literatura, Inglês, Francês, Espanhol), Filosofia, História, Pedagogia, Educação Física e Ciências Sociais.

Nos campi de Fortaleza, além das licenciaturas, a Universidade também oferta cursos de bacharelado, tais como Medicina, Enfermagem, Nutrição, Medicina Veterinária, Administração, Ciências Contábeis, Serviço Social, Psicologia, Ciências Sociais, Música e Filosofia. Já os campi localizados no interior do Ceará concentram apenas as licenciaturas. A maioria dos cursos ofertados pela Uece, portanto, está voltada para a formação de professores, o que requer dessa instituição pública de ensino superior uma maior preocupação com a dimensão pedagógica do trabalho docente e o compromisso com o desenvolvimento profissional daqueles que se formam profissionais não apenas para a atuação no mercado de trabalho, mas, sobretudo, para o exercício da docência, compreendida como profissão.

Feitas essas considerações, seguiremos com reflexões teóricas sobre saberes docentes e formação de professores e com a apresentação de resultados da pesquisa anteriormente mencionada, os quais foram obtidos a partir de estudos bibliográficos, documentais e de campo, realizados, principalmente, por meio de dissertações e teses constituídas no transcorrer da investigação e, também, do estágio pós-doutoral ${ }^{1}$ realizado por um dos autores do presente artigo sob supervisão do coautor. Todos esses estudos partiram do pressuposto da insuficiência da formação pedagógica para o exercício da docência no ensino superior, a qual, de acordo com Anastasiou (2006), conduz os docentes a repetirem com seus alunos o que viveram com seus professores, mantendo um ensino repetitivo e focado na exposição do conteúdo, o que compromete as possibilidades de avanços tanto daqueles que ensinam como dos que aprendem.

A docência superior, de acordo com Isaia (2006), é um processo complexo que se constrói no decorrer da trajetória docente, a qual envolve três dimensões inter-relacionadas: a dimensão pessoal, a profissional e a institucional. O processo formativo do professor compreende, portanto, desde suas relações interpessoais até suas experiências profissionais em instituições de ensino ao longo de sua carreira. Logo, envolve o desenvolvimento de esforços pessoais e institucionais. As instituições de ensino superior (IES) têm buscado organizar processos de formação permanente e de desenvolvimento profissional de seus docentes por meio de palestras, seminários, semanas pedagógicas, entre outras iniciativas. Contudo, estas não devem ocorrer de forma isolada, mas sim articuladas a um processo de construção coletiva de estratégias sistematicamente organizadas que permitam a constante reflexão crí-

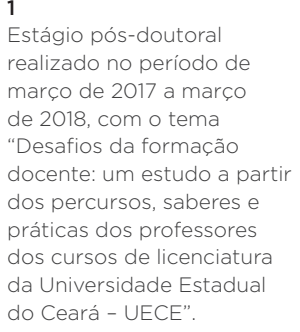


tica sobre o papel da universidade, os projetos pedagógicos e os saberes docentes inerentes ao processo de ensino-aprendizagem.

Desse modo, um dos propósitos da pesquisa apresentada neste artigo foi contribuir com o processo de formação de professores da Uece, o qual não pode ser pensado fora do cenário contemporâneo, marcado por insuficiente investimento do Estado na educação superior pública e pelas constantes lutas por melhores condições de trabalho e de infraestrutura que atendam às necessidades do corpo docente e discente, numa conjuntura em que os impactos da crise econômica e política que atingem o Brasil também se fazem presentes nas IES públicas. Crise essa que reflete um quadro mais amplo do capitalismo atual, entre cujos traços se destacam: desemprego estrutural; aumento da pobreza absoluta; perda de poder dos sindicatos; transnacionalização da economia; financeirização do capital; privatização de empresas e de serviços públicos; e conversão da ciência e da tecnologia em agentes de acumulação do capital (CHAUÍ, 2001).

É nesse quadro que ocorre a expansão da educação superior sob a lógica do mercado, a qual se expressa não só no aumento do número de instituições de ensino superior privadas, mas também na privatização interna das IES públicas, por meio da oferta de cursos pagos, como os mestrados profissionais, no financiamento público indireto para o setor privado, via Programa de Financiamento Estudantil (Fies), por exemplo, na certificação em larga escala, por meio de ações como a expansão do ensino a distância (EaD), no produtivismo que condiciona a política de pesquisa e de pós-graduação e, consequentemente, na intensificação do trabalho docente (LIMA, 2013).

Assim, os limites e desafios à formação de professores da e na Uece, para além de questões pessoais, profissionais e institucionais, passam por problemas conjunturais da realidade social que se refletem diretamente nas práticas docentes, tornando necessário o desenvolvimento de um conjunto de saberes que fundamentem o exercício da docência no contexto universitário, principalmente nos cursos de licenciatura, que têm como objetivo "ensinar a ensinar". É preciso, antes de tudo, compreender a aprendizagem contínua como uma exigência do trabalho docente. Afinal, conforme afirma Demo (2004, p. 36),

\footnotetext{
[...] professor não é quem ensina, mas o eterno aprendiz, aquele que aprende melhor, está à frente dos outros neste desafio, ou que faz disso sua própria profissão; cabe ao professor o direito de estudar durante o trabalho, porque é trabalho: quem não estuda não tem aula para dar; quem não reconstrói conhecimento, só pode repassar a sucata disponível; para que o aluno bem aprenda, é mister que conviva com professor que aprende bem.
} 


\section{SABERES DOCENTES E FORMAÇÃO DE PROFESSORES: ALGUMAS REFLEXÕES}

A formação, os saberes e as práticas docentes dos professores da Uece, inseridos no cenário anteriormente descrito, estão no foco das discussões e dos estudos realizados na e pela Universidade, a exemplo da pesquisa ora apresentada, em torno da qual se desenvolveram diversas dissertações e teses na área de Formação de Professores. Entre os teóricos mais destacados pelos pesquisadores envolvidos na referida pesquisa estão Gauthier et al. (2013), para quem a problemática do ensino

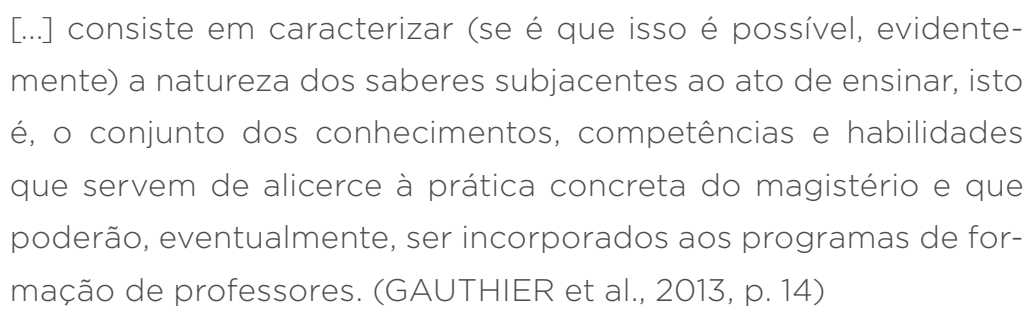

Com a perspectiva de estabelecer um repertório de conhecimentos que corresponda aos saberes profissionais próprios do professor, os autores refutam a ideia de que, para ser professor, basta conhecer o conteúdo, seguir a intuição e ter talento, bom senso, experiência e cultura. Para eles, são saberes necessários ao ensino: o saber disciplinar, referente aos saberes produzidos pelos pesquisadores e cientistas nas diversas disciplinas científicas; o saber curricular, que se refere aos programas escolares; o saber das ciências da educação, que corresponde aos saberes a respeito da escola e a noções sobre sistema escolar, classes sociais, diversidade cultural, etc.; o saber da tradição pedagógica, referente às representações da escola e da profissão que guiam os comportamentos dos professores; o saber experiencial, que diz respeito ao aprendizado dos professores por meio de suas próprias experiências; e o saber da ação pedagógica, que constitui um dos fundamentos da identidade profissional do professor, a partir do momento em que o saber experiencial se torna público e é testado pelas pesquisas realizadas em sala de aula (GAUTHIER et al., 2013).

Na concepção dos autores, a Pedagogia é compreendida como

\footnotetext{
[...] a codificação de determinados saberes próprios ao professor de profissão, isto é, como um conjunto de regras, de explicações, de conselhos metódicos que não podem ser confundidos com os conteúdos a serem ensinados, sem contudo excluí-los, e que são formulados expressamente para o professor com vistas a ajudá-lo a ensinar os alunos a fim de que estes "aprendam mais, mais rápido e melhor". (GAUTHIER et al., 2013, p. 294-295)
} 
Para Gauthier et al. (2013), a ciência pode ajudar a ultrapassar o saber experiencial que prevalece no campo da educação, sendo este comparado a uma jurisprudência privada, na perspectiva de criar e validar o saber da ação pedagógica, que corresponde a uma "verdadeira jurisprudência pública da Pedagogia”. Desse modo, eles estabelecem uma analogia entre o juiz e o professor, afirmando que:

\footnotetext{
[...] para que haja jurisprudência, é preciso não somente que sejam tomadas decisões, mas também que essas decisões sejam motivadas, visto que é justamente a motivação das decisões que permite compreender o sentido do julgamento e possibilita ao juiz subtrair-se à suspeita de arbitrariedade que pesa sobre essas decisões. Por isso, ele poderá, por meio da jurisprudência, recorrer às decisões já tomadas anteriormente em casos idênticos ou similares. (GAUTHIER et al., 2013, p. 310-311)
}

Em síntese, os autores acreditam que é preciso tornar público o saber experiencial dos professores, isto é, seus julgamentos e os motivos que os fundamentam, de modo a conhecer melhor seu raciocínio prático e formular leis de ensino que sejam formalizadas e institucionalizadas.

Outra referência importante para os pesquisadores foi Tardif (2002), segundo o qual os saberes profissionais dos professores têm algumas características particulares, configurando-se como saberes: temporais, evolutivos e progressivos, pois são adquiridos ao longo do tempo e requerem formação contínua e continuada; revisáveis, criticáveis e passíveis de aprofundamento; plurais, heterogêneos, sincréticos e ecléticos, quanto aos objetivos de ação; personalizados e situados, em relação a uma situação particular de trabalho; e que carregam as marcas do ser humano, pois o objeto do trabalho docente são seres humanos. Para o autor, há um conjunto de saberes (knowledge base) que designam o ato de ensinar no ambiente escolar e que provêm de fontes diversas: formação inicial e contínua; currículo e socialização escolar; conhecimento das disciplinas ensinadas; experiência na profissão; cultura pessoal e profissional; aprendizagem com os pares; etc. (TARDIF, 2002). Esse conjunto de saberes envolve, portanto, saberes curriculares, disciplinares, da formação profissional, experienciais e culturais.

É importante destacar que, segundo o autor, a noção de saber tem sentido amplo, envolvendo conhecimentos, competências, habilidades (aptidões) e atitudes dos docentes, isto é, o saber, o saber fazer e o saber ser (TARDIF, 2002). Nessa perspectiva, ele considera a experiência de trabalho e a própria história de vida do professor como fontes privilegiadas do saber ensinar. Concebendo os professores como "trabalhadores do ensino" e a Pedagogia como "tecnologia da interação humana" guiada por valores, o autor define o professor como "trabalhador intera- 
tivo", cujo objeto de trabalho são seres humanos e situações humanas, uma vez que "ensinar é, obrigatoriamente, entrar em relação com o outro" (TARDIF, 2002, p. 222).

O autor defende duas teses principais. A primeira é a de que "os professores são sujeitos do conhecimento e possuem saberes específicos ao seu ofício"; e a segunda é a de que sua prática "não é somente um lugar de aplicação de saberes produzidos por outros, mas também um espaço de produção, de transformação e de mobilização de saberes que lhe são próprios" (TARDIF, 2002, p. 237).

García (1999, p. 26), por seu turno, oferece importante contribuição no que diz respeito à formação de professores, tratando-a como uma área de conhecimento e investigação centrada no "estudo dos processos através dos quais os professores aprendem e desenvolvem sua competência profissional". Nesses processos, é preciso considerar a condição particular dos professores como pessoas adultas, que aprendem em situações e contextos diversos. Segundo o autor,

\footnotetext{
[...] não se pode afirmar que existe uma única teoria da aprendizagem do adulto. A teoria da aprendizagem do adulto que com maior frequência se tem comentado em relação à aprendizagem dos professores parece ser a "andragogia”, proposta por Knowles, e definida como "a arte e a ciência de ajudar os adultos a aprender". Knowles diferenciou mesmo a Andragogia da Pedagogia, sendo a primeira a ciência da educação dos adultos, enquanto a segunda seria a dos sujeitos não adultos. (GARCíA, 1999, p. 55)
}

García (1999) também aponta um repertório de conhecimentos necessários aos professores, incluindo: o conhecimento psicopedagógico, que se refere ao conhecimento relacionado com o ensino, com a aprendizagem e com os alunos (princípios gerais de ensino, gestão de classe, técnicas didáticas, teorias do desenvolvimento humano, avaliação, filosofia da educação, aspectos legais da educação); o conhecimento do conteúdo, isto é, o conhecimento sobre a matéria que ensinam; o conhecimento do contexto, ou seja, das características socioeconômicas e culturais do bairro, das expectativas dos alunos, da cultura da escola e de suas normas de funcionamento, entre outros aspectos; e o conhecimento sobre os alunos (sua procedência, os níveis de rendimento em cursos prévios, sua implicação na escola), o qual se adquire em contato com os alunos e com as escolas reais.

Ao considerar as diferentes fases da carreira dos professores e suas características, o autor afirma: 


\begin{abstract}
Conceber a formação de professores [...] como um "processo contínuo, sistemático e organizado" significa entender que a formação de professores abarca toda a carreira docente. Falar da carreira docente não é mais do que reconhecer que os professores, do ponto de vista do "aprender a ensinar", passam por diferentes etapas (pré-formação, formação inicial, iniciação e formação permanente, de acordo com Feiman, 1983), as quais representam exigências pessoais, profissionais, organizacionais, contextuais, psicológicas, etc., específicas e diferenciadas. (GARCíA, 1999, p. 112)
\end{abstract}

Em síntese, de acordo com García (1999), a formação de professores é um processo que abarca todas as etapas da carreira docente, as quais correspondem a diferentes fases na vida dos professores: entrada na carreira, estabilização, experimentação ou diversificação, procura de uma situação profissional estável e preparação da jubilação. Desse modo, ela deve ser integrada em processos de mudança, inovação e desenvolvimento curricular, articulada com o desenvolvimento organizacional da instituição de ensino, baseada nas necessidades e interesses dos participantes e adaptada ao contexto em que estes trabalham, oferecendo-lhes a possibilidade de questionarem suas próprias crenças e práticas.

\title{
FORMAÇÃO, SABERES E PRÁTICAS DOCENTES DOS PROFESSORES DA UECE EM QUESTÃO
}

Foi com base nas contribuições dos autores supracitados e de tantos outros que pesquisadores como Miranda (2016), Santos (2017), Varela (2017), Maciel (2017) e Silva Neta (2018) realizaram seus estudos sobre a temática em questão no âmbito da pesquisa referenciada, a qual também resultou em alguns dados quantitativos relacionados aos 629 professores que ministraram disciplinas pedagógicas na Uece entre 2003 e 2015. Desse total, 359 (57,07\%) lecionaram nos campi do Itaperi e de Fátima, localizados na cidade de Fortaleza; 22 (3,50\%), na Faculdade de Educação, Ciências e Letras dos Inhamuns (Cecitec), no município de Tauá; 30 (4,77\%), na Faculdade de Educação de Itapipoca (Facedi); 30 (4,77\%), na Faculdade de Educação de Crateús (Faec); 81 (12,88\%), na Faculdade de Filosofia Dom Aureliano Matos (Fafidam), situada em Limoeiro do Norte; 68 (10,81\%), na Faculdade de Educação, Ciências e Letras do Sertão Central (Feclesc), em Quixadá; e 39 (6,20\%), na Faculdade de Educação, Ciências e Letras de Iguatu (Fecli).

No que se refere à titulação dos professores pesquisados, 26 (5\%) são graduados, 73 (12\%) especialistas, 274 (44\%) mestres, 223 (35\%) doutores e 33 (5\%) não tiveram sua titulação identificada. Quanto à formação inicial, 436 (69\%) professores são licenciados, dos quais 50 
possuem também bacharelado, 77 (12\%) são bacharéis e 116 (19\%) não tiveram suas formações iniciais encontradas nos documentos examinados, tais como seus respectivos currículos Lattes. No que diz respeito ao regime empregatício dos 629 professores analisados, 289 (46\%) são efetivos na Uece, 308 (49\%) são substitutos e 32 (5\%) não tiveram seu vínculo com a instituição identificado. Em relação à pós-graduação, dos 436 professores licenciados que ministraram disciplinas pedagógicas na Uece, 206 (47\%) têm essa formação acadêmica em Educação e 230 (53\%) não possuem. Já em relação aos bacharéis, dos 77 envolvidos, tais valores correspondem a, respectivamente, 25 (32\%) e 52 (68\%). Quanto à pós-graduação dos professores que não tiveram sua formação inicial identificada, dos 116 professores analisados, 15 (12\%) têm esse tipo de formação em Educação, 49 (42\%) não têm e 52 (45\%) não tiveram sua pós-graduação identificada.

Miranda (2016) estudou o percurso formativo, o repertório de saberes e as práticas docentes dos professores da área de História e Ensino do curso de Licenciatura em História da Uece, em Fortaleza. Sua proposta metodológica consistiu num estudo de caso único com sujeitos múltiplos e uso de fontes documentais, entrevistas semiestruturadas com seis professores do curso de História e observação de aulas ministradas por duas professoras nas disciplinas de Didática do Ensino de História e Metodologia do Ensino de História, no período entre junho e agosto de 2015. Os resultados de suas pesquisas bibliográfica e documental apontaram para um histórico processo de secundarização da formação docente nas licenciaturas em História no Brasil, com poucos momentos formativos voltados para o ensino. Já a pesquisa de campo indicou um variado repertório de percursos formativos e saberes mobilizados nas práticas docentes dos sujeitos envolvidos, os quais promovem a formação de professores em um curso de perfil mais próximo de um bacharelado, sem privilegiar seus saberes da ação pedagógica; alguns sujeitos entrevistados destacaram seus saberes da experiência e outros apontaram seus saberes históricos como os mais mobilizados em suas aulas.

Em relação ao percurso formativo dos professores do caso analisado, sua formação escolar, ocorrida entre as décadas de 1950 e 1980, foi marcada pelo aulismo tradicional, centrada na oralidade e nas formas de avaliação escritas, com pouca problematização. As aulas de História que tiveram foram produtos de "seus tempos", marcados por um ensino ainda baseado em datas e fatos; raramente a História dita crítica apareceu. Algumas motivações particulares os conduziram a escolher o curso de História, como presença de professores na família e influência de alguns docentes marcantes. No que diz respeito à formação inicial, entre os anos 1970 e o início da década de 1990, eles destacaram a vivência da cultura bacharelesca nos cursos de licenciatura, disciplinas 
de formação didático-pedagógica desarticuladas da formação específica, estágios pouco significativos e exercício da docência concomitante à formação inicial. Em relação à formação continuada, quase todos os professores, na época da pesquisa, eram especialistas (exceto um), sendo três em Educação e cinco em temáticas de História; cinco mestres e um mestrando, sendo dois em Educação, um em Sociologia e dois em História; quatro doutores, dos quais três em História e um em Educação; uma pós-doutora e um pós-doutorando.

Quanto aos objetos de pesquisa, nenhum pesquisou sobre sua própria prática docente. Todos estavam no ensino superior há mais de 20 anos e possuíam vasta formação contínua, destacando-se: as leituras por eles realizadas (mais historiográficas do que em Ensino de História e História da Educação); a participação em eventos, congressos e outras atividades em torno de temáticas de Ensino de História; a aprendizagem via saberes da experiência em escolas da educação básica; e as variadas formas de formação em serviço (mais voltadas para as disciplinas do que para a formação docente). Todos eles se pós-graduaram após o ingresso no ensino superior, algo considerado cada vez mais raro.

Sobre os saberes docentes, os saberes curriculares se manifestaram nas falas de todos os professores e apareceram como conteúdos nas aulas de duas professoras. Saberes da tradição escolar foram mobilizados nos relatos sobre a formação escolar. Saberes das ciências da Educação foram pouco mobilizados nas entrevistas, porém apareceram nas aulas de duas professoras. Saberes da experiência constituem saberes fortes e consolidados por todos os professores, mas mobilizados de formas peculiares, incluindo saberes experienciais oriundos da educação básica regular, do ensino superior via docência e do ensino superior via gestão. Quanto aos saberes da ação pedagógica, os professores se posicionaram na perspectiva de um Ensino de História dito crítico, com elementos de Ensino de História mediado por fontes, embora nem todas as aulas sejam mediadas por problematizações e pelo contato com fontes.

Por fim, no que se refere às práticas docentes, o pesquisador identificou, por meio da observação das aulas de professores, múltiplas tendências de planejamento das disciplinas. Quanto aos recursos e metodologias de ensino, há maior recorrência de aulas expositivas dialogadas do que de aulas problematizadas, de acordo com as entrevistas. Há predominância de metodologias de ensino mistas entre um Ensino de História dito crítico e um Ensino de História mediado por fontes. Sobre as práticas avaliativas, identificou-se uma variedade de formas de verificação da aprendizagem: instrumentos escritos, como provas, relatórios, portfólios, etc.; instrumentos orais programados e avaliações orais não instrumentalizadas; e práticas de autoavaliação, inclusive por parte dos próprios professores. 
Santos (2017), por sua vez, fez uma cartografia dos percursos formativos dos professores que compõem a área de "História e Ensino" da Faculdade de Educação, Ciências e Letras do Sertão Central (FECLESC) Uece), a partir de suas falas, de informações encontradas em seus currículos Lattes e em editais de concursos dos quais participaram. Os saberes mobilizados nas práticas pedagógicas dos sujeitos investigados contemplam um repertório variado, contudo os saberes pedagógicos, imprescindíveis à formação dos profissionais para a docência no ensino superior, não foram contemplados em todas as falas. Quanto ao perfil dos seis professores que compõem a área de "História e Ensino" da FECLESC/Uece, três são homens e três são mulheres; todos formados em História por instituições públicas de ensino superior; dois têm entre 7 e 12 anos de experiência com docência na educação básica, dois possuem reduzida vivência (de 1 a 2 anos) e dois não têm; cinco professores são efetivos e apenas um é substituto; três têm entre 10 e 16 anos de experiência no ensino superior, dois têm entre 4 e 6 anos de experiência e um possui dois anos de experiência.

Tomando como parâmetro os estudos de Huberman (2000), que aponta os ciclos na vida profissional de professores com base nos anos de experiência, a pesquisadora depreende que: três estão na etapa denominada de "fase da experimentação e diversificação", marcada pela busca de atualização e de melhores expectativas profissionais, assim como pelas interrogações peculiares da metade da carreira; dois professores encontram-se na "fase da estabilização", aquela na qual se consolidam as habilidades, o compromisso com as escolhas profissionais, a autonomia e a segurança no enfrentamento das situações e, principalmente, consolidam-se a prática pedagógica e a forma de ser professor; e, por fim, um professor está no que o autor denomina de "fase de início da carreira", caracterizada pela "sobrevivência" e "descoberta", que envolve os três primeiros anos de docência (SANTOS, 2017). Outro aspecto considerado importante na pesquisa é que quatro docentes adentraram na FECLESC por meio de seleções públicas para professor substituto, sendo que três deles participaram depois de concurso público para professor efetivo da Uece, sendo aprovados e nomeados posteriormente.

Os saberes adquiridos na formação inicial, associados às experiências de vida próprias e diferenciadas, aos saberes provenientes da participação em grupos de estudos, estágios supervisionados, atividades de pesquisa, monitoria, entre outras, e aos saberes oriundos da pós-graduação e da experiência de sala de aula na educação básica e no ensino superior, possibilitaram aos professores o desenvolvimento da prática docente ao longo de sua carreira. A pesquisadora conclui que o interesse pela formação inicial em História teve motivações muito diferentes entre os professores, que apontaram desde suas experiências de criança e a influência de professores que marcaram de forma significa- 
tiva suas vidas quando eram jovens, até circunstâncias próprias da vida já na fase adulta (SANTOS, 2017). A forma como cada um se apropriou dos saberes formativos em suas vidas escolares também foi diferenciada, revelando características das escolas, dos cursos, dos professores, das principais leituras e das influências que tiveram.

Quanto à relação entre saberes, formação e práticas, os sujeitos enfatizaram diferentes aspectos, tais como vivências nos estágios ainda como estudantes de graduação, tempo de experiência na educação básica e no ensino superior e tempo de dedicação às disciplinas da área de "História e Ensino". Os saberes pedagógicos não foram contemplados em todas as falas, sendo pouco privilegiados no repertório de saberes mobilizados pelos professores. Apesar de os cinco professores entrevistados terem feito o curso de licenciatura em História, o relato de três deles deixou claro que a formação pedagógica do curso não foi capaz de oferecer orientações sobre como ensinar, lacuna esta que foi superada na prática, a partir de situações concretas de ensino. Um aspecto bastante comum, principalmente no início da carreira dos professores universitários, é a reprodução do exercício da docência, isto é, a repetição de métodos, recursos pedagógicos e características de outros professores, com recorrência à interpretação da visão de docência que tiveram como estudantes. Assim como Gauthier et al. (2013), a pesquisadora assume a necessidade de revelar e validar os saberes da experiência docente, a fim de que esses não permaneçam circunscritos às práticas individuais dos professores, mas sejam socializados, de modo a se tornarem úteis nos processos de formação docente e na constituição de um perfil de professor universitário (SANTOS, 2017).

Tendo como objeto de investigação o fazer-se professor de "ensino de", junto a docentes de disciplinas pedagógicas em cursos de licenciatura (Química, Biologia e Pedagogia) da Faculdade de Educação de Itapipoca (Facedi/Uece), Varela (2017) parte da hipótese de que os cursos de licenciatura se revestem de características de bacharelado, deixando em segundo plano o objetivo de formar licenciados. Desse modo, a pesquisadora questiona se, de fato, o professor universitário possui formação para planejar, ministrar aulas e avaliar, já que é isso que frequentemente se espera de um docente.

Ao estabelecer um quadro de estudos relacionados à sua temática investigativa, realizando o estado da questão, a autora chega a alguns achados que sinalizam a preponderância da formação para a pesquisa em detrimento do ensino, assim como a predominância de saberes conceituais e procedimentais em detrimento de saberes pedagógicos, apontando a necessidade de debater o trabalho e a formação do professor universitário (VARELA, 2017). Os resultados investigativos indicam, também, que a prática dos sujeitos pesquisados se fundamenta nas experiências e os seus saberes estão pautados na cópia de modelos 
de docência considerados positivos e/ou na não repetição de modelos entendidos como negativos.

A pesquisadora chama a atenção para o fato de que o profissional ingressa na universidade e é entregue à própria sorte, com programas de disciplinas com ementas prontas, planejando o ensino de maneira solitária e sem direcionamentos (VARELA, 2017). Ademais, os mestrados e doutorados têm preocupação marcante com a formação do pesquisador e a docência fica em segundo plano. Nesse sentido, a formação pedagógica dos professores precisa ser institucionalizada, pois não se pode conceber o desenvolvimento profissional somente como uma atitude individual do docente em busca de melhorias para sua prática. Quando o foco são professores universitários responsáveis pela formação de novos docentes, a preocupação aumenta. É necessário constituir uma cultura institucional que possibilite o desenvolvimento profissional docente, pois trata-se de um processo permanente e depende de políticas da instituição viabilizadoras de propostas formativas e de valorização da profissão docente.

A pesquisa de Maciel (2017), por seu turno, buscou cartografar a trajetória formativa, os saberes e as práticas avaliativas de professores que ministram as disciplinas pedagógicas no curso de Matemática do campus do Itaperi/Uece. Ao realizar o estado da questão, a pesquisadora chega a algumas observações iniciais: a temática da avaliação é pouco importante como elemento curricular constituinte da preparação docente nos cursos pesquisados; há necessidade de ações formativas, no caso dos professores pesquisados, favorecendo o conhecimento mais abrangente a respeito da docência; os docentes envolvidos consideraram que não foram devidamente preparados para desenvolverem a avaliação com seus alunos, sendo a maioria dos docentes de cursos de licenciatura; num panorama geral, as pesquisas selecionadas que tratam de avaliação revelaram que os professores universitários recorrem aos exames ou à verificação de aprendizagem; com relação à formação do professor, a ausência de discussões sobre avaliação da aprendizagem em matemática na graduação e na pós-graduação implica a manutenção de concepções e práticas avaliativas tradicionais; as aprendizagens dos estudantes estão envoltas na perspectiva técnica de avaliação, centrada nos instrumentos e concebida como mera verificação da aprendizagem; há ausência de pesquisas que envolvam as universidades estaduais (MACIEL, 2017).

A temática da avaliação também está no foco da pesquisa de Silva Neta (2018), com o objetivo de cartografar os saberes, as práticas e a formação que constituem o conhecimento avaliativo dos docentes dos sete cursos de Pedagogia ofertados pela Uece, sendo um na capital, no Centro de Educação (CED), e seis no interior do Ceará (Faec, Facedi, Fecli, Feclesc, Fafidam e Cecitec). Os sujeitos da pesquisa são docentes 
das disciplinas de Didática e Avaliação e licenciandos que já cursaram as duas disciplinas supracitadas. A pesquisadora parte do princípio de que existem disciplinas específicas que devem trabalhar o conhecimento avaliativo na licenciatura em Pedagogia, sendo que os conhecimentos avaliativos dos professores dependem da adequação de formação, dos saberes e práticas, com possibilidades de afetar a formação do pedagogo na área de avaliação (SILVA NETA, 2018). Na pesquisa com professores do curso de Pedagogia, constatou-se o desconhecimento de alguns docentes acerca dessa temática, especificamente por dois fatores: desconhecimento do conceito de avaliação e por acreditarem que avaliação corresponde à verificação da aprendizagem, resumindo-se à aplicação de instrumentos como provas e trabalhos (SILVA NETA, 2018).

A autora parte do pressuposto de que a avaliação do ensino e da aprendizagem é útil tanto para os professores como para os discentes, na medida em que, aos primeiros, permite a reflexão sobre a prática e a análise da coerência entre os objetivos definidos e os resultados obtidos, orientando a tomada de decisões favoráveis à aprendizagem dos estudantes, e, a estes últimos, proporciona o conhecimento de como está sua aprendizagem, do que deixou de aprender e, principalmente, das consequências que tais fatos acarretam em sua formação (SILVA NETA, 2018). Para ela, o conhecimento avaliativo está vinculado aos aspectos apreendidos na formação inicial e continuada, sendo que os docentes, na maioria das vezes, não têm consciência de que sua formação é uma reprodução dos valores e crenças repassados por seus professores nas escolas e nas universidades, norteando sua prática profissional (SILVA NETA, 2018). A constituição do conhecimento avaliativo se inicia durante o curso de graduação, perpassando toda sua trajetória docente. Isso implica dizer que os sujeitos aprendem a ensinar e avaliar com seus professores e com seus pares.

Em relação à formação de professores, a pesquisadora enfatiza que, além das teorias e dos conteúdos ensinados, também é relevante que os estudantes obtenham conhecimento acerca do planejamento, do ensino, da metodologia e da avaliação, compreendendo que estes são elementos constituintes do trabalho docente (SILVA NETA, 2018). Desse modo, faz-se necessário que a avaliação seja abordada nos cursos de licenciatura também em seu aspecto didático-pedagógico, e não somente para quantificar os conteúdos ou como atividade técnica para coleta de dados.

De fato, os conhecimentos avaliativos estão entre aqueles que mais desafiam os professores em sua prática docente. Não por acaso, tais conhecimentos, assim como os relacionados ao planejamento do ensino, apareceram entre os mais citados entre as sugestões de conteúdos para formação docente dos professores que participaram do I Curso 
de Formação para Novos Docentes da Uece, promovido pela Pró-reitoria de Graduação (Prograd) em fevereiro de 2017.

Tal curso, sob coordenação de um dos autores do presente artigo (então coordenadora da Célula de Assessoramento Pedagógico da Prograd/Uece) e com participação do coautor como um dos facilitadores, abordou os seguintes aspectos e temáticas: acolhimento dos docentes que ingressaram nos últimos concursos para professores efetivos da Uece; apresentação da Fundação Universidade Estadual do Ceará (Funece) como instituição pública integrada ao governo do estado do Ceará; direitos e deveres do servidor público estadual; direitos e deveres do servidor docente da Funece; currículo e projeto pedagógico de curso (PPC); a Andragogia e os desafios da docência no ensino superior; planejamento e avaliação no trabalho docente; metodologias ativas no ensino superior; e tecnologias da informação e da comunicação (TIC) no ensino superior.

Ao final do curso solicitou-se aos participantes o preenchimento de um questionário, por meio eletrônico, no intuito de avaliar tal ação formativa integrada ao Plano de Desenvolvimento Profissional Docente (PDPD) da Uece, ${ }^{2}$ na época em processo de construção coletiva, com participação dos colegiados dos cursos e da administração superior da Universidade, sob coordenação da Prograd. O questionário incluiu cinco questões abertas abrangendo: aprendizagens mais significativas do curso; aspectos abordados durante o curso aplicáveis direta ou indiretamente à prática docente dos participantes; sugestões para o próximo Curso de Formação para Novos Docentes da Uece; sugestões sobre outras ações de formação para a efetivação do PDPD; e temáticas que devem ser priorizadas nessas ações. Dos 110 participantes do curso, 80 responderam ao questionário.

A Uece, por meio da Pró-Reitoria de Graduação, realizou a referida ação de formação para os professores, utilizando como referência resultados da pesquisa apresentada neste artigo. Objetivando a melhoria dos processos formativos dos professores da IES, foram solicitadas aos participantes sugestões de outras ações formativas voltadas para o seu desenvolvimento profissional como docentes, sendo apontadas estratégias como: promoção de cursos, fóruns, palestras, oficinas e minicursos sobre diferentes temas educacionais; inclusão de semanas pedagógicas no calendário acadêmico da Universidade; ações de capacitação à distância; realização de oficinas pedagógicas para planejamento e avaliação das atividades docentes; formação para orientadores de pesquisas e supervisores de estágio curricular; cursos voltados especialmente para os professores dos cursos de licenciaturas da Uece, entre outras.

Sobre as temáticas que devem ser priorizadas em tais ações de formação, os participantes elencaram: educação superior; saberes do- 
centes; construção da carreira docente; psicologia da educação; ética profissional; legislação educacional; educação inclusiva e acessibilidade no ensino superior; estágio supervisionado; trabalho de conclusão de curso; relacionamento interpessoal; reforma do ensino médio e seus impactos nas licenciaturas; instrumentos de avaliação; elaboração de currículos; avaliação da aprendizagem; pesquisa educacional; educação à distância; gestão acadêmica; multidisciplinaridade, interdisciplinaridade e transdisciplinaridade na docência no ensino superior; metodologias ativas e inovações tecnológicas no processo de ensino-aprendizagem; Andragogia; gestão do ensino superior; planejamento; didática; direitos humanos; diversidade racial, sexual, religiosa e cultural; Língua Brasileira de Sinais (Libras); entre outras que apontam os saberes necessários ao exercício da docência no ensino superior e, especialmente, as principais demandas de formação dos professores da Uece.

\section{CONSIDERAÇÕES FINAIS}

A pesquisa "Cartografia das relações de saber/poder dos professores das licenciaturas" envolveu diversos trabalhos investigativos com o objetivo de estudar a formação, os saberes e as práticas docentes dos professores de diversos cursos de licenciatura da Uece.

Em linhas gerais, os estudos realizados no âmbito dessa pesquisa revelam deficiências e insuficiências na formação pedagógica dos professores dos cursos de licenciatura da IES, os quais acabam assumindo muito mais características de cursos de bacharelado, direcionados à preparação de profissionais de diferentes áreas do conhecimento para a pesquisa e a atuação no mercado de trabalho, do que de cursos especificamente voltados para ensinar a ensinar, apontando, assim, limites e desafios para a formação de professores que formam professores.

Observe-se que os cursos que formaram os professores da Uece atribuíram maior ênfase aos saberes disciplinares, relacionados aos conteúdos conceituais e procedimentais de determinadas disciplinas científicas, em detrimento de conteúdos pedagógicos, responsáveis pela transposição do saber científico ao saber escolar, tão necessária ao exercício da docência. E como os saberes da ação pedagógica são pouco socializados e mobilizados por esses professores, eles acabam reproduzindo os saberes da tradição e da experiência e, por consequência, formando futuros professores sem a devida formação pedagógica para a prática docente na educação básica.

Em síntese, a formação inicial dos professores dos cursos de licenciatura da Uece parece não lhes ter ensinado a ensinar, uma lacuna que eles buscaram suprir com os saberes experienciais, frutos de suas próprias vivências profissionais. Por conseguinte, como a tendência que se observa é a repetição das práticas de seus professores tanto da edu- 
cação básica como da superior, segundo suas interpretações pessoais do que seja positivo e negativo em tais práticas, eles também formam professores sem priorizar a formação pedagógica. A própria forma como foram selecionados para serem professores de cursos de licenciatura prioriza conteúdos específicos de cursos de bacharelado, com pouca ênfase nos aspectos pedagógicos, mesmo aqueles selecionados para ensinar disciplinas especificamente pedagógicas.

Esse é um aspecto comum dos estudos aqui apresentados, embora tenham aparecido na fala dos interlocutores múltiplas trajetórias e experiências de vida, bem como diferentes escolhas, influências e motivações para o exercício da docência, uma profissão que requer não só formação inicial de qualidade, mas também formação continuada e contínua com participação efetiva das instituições de ensino, as quais devem assumir o compromisso com o processo formativo do seu corpo docente e, por conseguinte, com a melhoria do processo de ensino-aprendizagem dos discentes.

No contexto da universidade pública e, especialmente, da Uece, para além do planejamento do ensino propriamente dito (que inclui a gestão do conteúdo e da sala de aula) e da avaliação, tais atividades envolvem, também, a gestão acadêmico-administrativa, a elaboração e o acompanhamento de projetos de pesquisa, de monitoria e de extensão, a orientação de estudantes, a supervisão de estágio, entre outras que desafiam os professores universitários a buscarem soluções para os problemas que enfrentam cotidianamente, como, por exemplo, o aumento da contratação de professores substitutos em detrimento da realização de concursos públicos para professores efetivos. Isso não só aumenta a rotatividade de profissionais que ingressam nos cursos de graduação como docentes, por meio de relações de trabalho precárias e instáveis, como também intensifica o trabalho docente de substitutos e efetivos, dada a carência de um número suficiente de professores para exercer todas as atividades acima elencadas.

Há, ainda, a insuficiência de recursos para suprir as demandas institucionais da Universidade, inclusive aquelas que se referem à formação profissional docente, o que ocorre devido à redução de investimentos estatais nos serviços públicos e, especialmente, na educação superior, a qual foi transformada num lucrativo negócio nos últimos anos, diante da ainda elevada expectativa do diploma de ensino superior como passaporte para ascensão social diante do desemprego estrutural. Este último, no entanto, atinge pessoas com todos os níveis de qualificação, dos analfabetos aos mestres e doutores, contribuindo para a precarização cada vez maior das condições de trabalho da classe trabalhadora, da qual fazem parte os profissionais da docência. 


\section{REFERÊNCIAS}

ANASTASIOU, Léa das Graças Camargos. Docência na educação superior. In: RISTOFF, Dilvo; SEVEGNANI, Palmira. Docência na Educação Superior. Brasília: Inep, 2006. p. 147-171. (Educação Superior em Debate, v. 5).

CHAUÍ, Marilena. Escritos sobre a universidade. São Paulo: Editora da Unesp, 2001.

DEMO, Pedro. Universidade, aprendizagem e avaliação: horizontes reconstrutivos. Porto Alegre: Mediação, 2004.

GARCÍA, Carlos Marcelo. Formação de professores. Para uma mudança educativa. Porto: Porto, 1999. (Ciências da Educação Século XXI, v. 2).

GAUTHIER, Clermont et al. Por uma teoria da pedagogia: pesquisas contemporâneas sobre o saber docente. Tradução Francisco Pereira. 3. ed. Ijuí: Ed. Unijuí, 2013. (Fronteiras da Educação).

HUBERMAN, Michaël. O ciclo de vida profissional dos professores. In: NÓVOA, António (Org.). Vidas de professores. 2. ed. Porto: Porto, 2000. p. 31-61. (Ciências da Educação).

ISAIA, Silvia Maria de Aguiar. Desafios à docência superior: pressupostos a considerar. In: RISTOFF, Dilvo; SEVEGNANI, Palmira. Docência na educação superior. Brasília: Inep, 2006. p. 63-84. (Educação Superior em Debate, v. 5).

LIMA, Kátia. Expansão da educação superior brasileira na primeira década do novo século. In: PEREIRA, Larissa Dhamer; ALMEIDA, Ney Luiz Teixeira de (Org.). Serviço social e educação. 2. ed. Rio de Janeiro: Lumen Juris, 2013. (Coletânea Nova de Serviço Social).

MACIEL, Alessandra de Oliveira. Cartografia da formação, saberes e práticas avaliativas de professores no curso de matemática. Texto de qualificação de projeto de dissertação (Mestrado) Universidade Estadual do Ceará, Fortaleza, 2017.

MIRANDA, Augusto Ridson de Araújo. Formação, saberes e práticas dos professores da área de ensino de história no curso de história da UECE em Fortaleza. 2016. 361 f. Dissertação (Mestrado em Educação) - Universidade Estadual do Ceará, Fortaleza, 2016.

SANTOS, Maria Terla Silva Carneiro dos. Saberes, práticas e formação: uma cartografia dos professores da área de "História e Ensino" da FECLESC/ UECE. 2017. 227 f. Dissertação (Mestrado em Educação) - Universidade Estadual do Ceará, Fortaleza, 2017.

SILVA NETA, Maria de Lourdes da. O conhecimento avaliativo dos docentes dos cursos de pedagogia: cartografia dos saberes, práticas e formação. Tese (Doutorado) - Universidade Estadual do Ceará, Fortaleza, 2018.

TARDIF, Maurice. Saberes docentes e formação profissional. Petrópolis, RJ: Vozes, 2002.

VARELA, Sarah Bezerra Luna. Docência universitária em cursos de licenciatura: cartografias de percursos formativos, constituição de saberes e vivências de práticas pedagógicas. Texto de qualificação de projeto de tese (Doutorado) - Universidade Estadual do Ceará, Fortaleza, 2017.

Recebido em: 26 MARÇO 2018 | Aprovado para publicação em: 04 JULHO 2018 